\title{
MATHEMATICAL WORD PROBLEMS THAT CONTAIN A CONSTANT IN THE COURSE OF MATHEMATICS OF PRIMARY SCHOOL IN UKRAINE
}

\author{
SVITLANA SKVORTSOVA, OKSANA ONOPRIENKO, RUSLANA ROMANYSHYN
}

\begin{abstract}
The article is devoted to the research of the place of the mathematical word problems in the course of mathematics of primary school in Ukraine. The researchers define the results in the study of solving math problems, find out the essence of the process of solving math problems, form primary school students' ability to solve math problems that contain a constant. Among the mentioned are to find the fourth proportional, do the proportional division and find the unknown number by two differences. The paper deals with the organization of educational research of students in order to identify common and distinctive features of the mathematical structures of these types of math problems and their influence on the method of solution. Based on the methodological system of teaching primary school learners to solve math problems by S. Skvortsova, taking into account the essence of the concept of "ability to solve math problems" and the methodical system of forming the ability to solve certain types of math problems, it has been proposed a system of drilling activities for the generalization of mathematical structures and methods of solving math problems that contain a constant value.
\end{abstract}

Keywords: mathematics, primary school, mathematical word problems, the math problem on finding the fourth proportional, the math problem on proportional division, the math problem on finding the unknown number by two differences.

\section{INTRODUCTION}

In 2018, the Government of Ukraine approved the new State Standard for Primary Education [1]. This document defines the goal of the mathematical educational field, which involves the formation of mathematical and other key competencies in students. Among the learning outcomes are the ability of pupils:

- to study situations and identify problems that can be solved using mathematical methods;

- to model processes and situations;

- to develop action strategies for solving various math problems;

- to critically evaluate the data, process and result of the solution of educational and practical problems;

- to apply the experience of mathematical activity to the study of the surrounding world;

- to make informed choice.

To achieve the mentioned goal, the special role in teaching of primary school students is played by solving mathematical word problems. 


\section{Ability to Solve Mathematical Word Problems as a Mandatory Learning OUTCOME IN THE PRIMARY SCHOOL OF UKRAINE}

\subsection{Mathematical (Word, ARithmetic) Problems in the COURSE OF MATHEMATiCs OF PRIMARY SCHOOL IN UKRAINE}

In accordance with the new State Standard two versions of the Core Curriculum for the first (Grades 1 and 2) and the second (Grades 3 and 4) cycles of the primary education were developed [2,3].

We were the developers of the mathematical education field of the first version of the Core Curriculum. For the development of students' ability to solve mathematical word problems the content area "Mathematical Problems and Research" was introduced in the curriculum. For each year of study, the types of mathematical word problems that pupils have to solve as well as actions and operations that students must do to solve a math problem are identified. In Grade 1, on the basis of simple problems (solved by one arithmetic action) learners develop the following skills: to solve simple mathematical word problems that are models of real situations; to create an auxiliary model of the math problem in different ways; to evaluate with teacher help the correctness of the problem; to design simple mathematical word problems. In Grade 2, the skills acquired in the previous year of learning are developing and improving. The development is enhanced through the inclusion of complex mathematical word problems (solved by several arithmetic actions) in the content of the study. This will be manifested in the following outcomes: solving simple and compound math problems; creating an auxiliary model of the math problem in different ways; planning how to solve the word problem; creating a mathematical model of the problem; evaluating with teacher help the correctness of the solution of the math problem; searching different methods for solving the math problem; designing mathematical word problems. Actions and operations for creating a problem auxiliary model, planning the math problem solving, and creating a mathematical model reveal the essence of the process of solving the math problem; therefore, the purpose of the first cycle of primary education is to form a general skill in solving mathematical word problems. Having implemented the necessary actions and operations in solving math problems, pupils of Grade 3 are ready for the generalizing of mathematical structures as well as methods of solving typical math problems. During the 3rd year of studying, learners are practising in solving the following mathematical word problems: on finding the fourth proportional, on the double reduction to one, and on the collaborative work. The task of the teacher is to teach students to explore and solve such math problems, as well as to make an expression to the problem with the letter data and to make inverted problems to the given one.

In Grade 4, other methods of solving typical math problems than those studied in Grade 3 or the same ones but with complicated mathematical structures are considered. In addition, new typical math problems are introduced: problems on proportional division, finding the unknown number by two differences, and on motion. It should also be noted that in Grades 3-4 along with the ability to solve typical math problems the work on developing general ability to solve problems on the material of problems containing fractions continues. A primary school graduate is expected to solve simple and compound mathematical word problems; to solve math problems on finding the fourth proportional by different methods, on double reduction to one, on proportional division, on finding the unknown number by two differences, on collaborative work, on the straight-line uniform motion of two bodies; to solve math problems with the letter data, and to make and solve inverted problems to the given one.

Thus, mathematical word problems are an integral part of the primary school mathematics course; therefore, we are interested in the problem of constructing an effective method of forming the ability to solve math problems in primary school students.

\subsection{Classification of MATHEMATICAL WORd Problems in the COURSE OF MATHEMATICS OF PRIMARY SCHOOL}

In the Core Curriculum, it has been determined that primary school graduates should acquire skills in solving simple, compound, and typical math problems. Particular attention to solving math 
problems as a means of forming the system of mathematical concepts, selection of tasks in secondary school textbooks at different times was paid by such scientists as G. Bevz (2003), Yu. Kolyagin (1977), Z. Slepkan (2000, 2003), A. Stolyar (1974), L. Friedman (2002) and others. In the context of primary school, this problem was studied by M. Bantova (1984), M. Bogdanovich (2006), N. Istomina (1986), D. Klimentchenko (1977), M. Moro (1978), L. Kochina (2002, 2004), A. Pcholko (1963), L. Skatkin (1963), S. Skvortsova (2006, 2011), P. Erdniev (1988) and others.

Based on the analysis of the works of the abovementioned authors, we propose a classification of mathematical word problems, which is an improvement of the generally recognized in Ukraine, Russia and Belarus, namely the division of all mathematical word problems into two classes - simple and compound. Within the framework of the compound math problems of the elementary mathematics course, the following typical math problems are distinguished: on finding the fourth proportional, on proportional division, on finding the unknown number by two differences, on double reduction to one, on collaborative work and on motion. We [4] justified the possibility of combining all the typical math problems into two groups: 1) math problems containing a constant: 2) math problems on processes.

The problem of classifying mathematical word problems and presenting them in mathematics textbooks for primary school is also relevant for the world didactics of mathematics. So, Kamuran AGRICULTURE Cukurova University, Mathematics Education Department, Istanbul,Turkey [5], studying the levels of solving mathematical word problems, the questions of which are answered by the arithmetic action of addition or subtraction, resorted to an analysis of the types of mathematical word problems offered to students in textbooks on mathematics. D. Rohrer and K. Taylor [6] also analyze the subject matter of textbooks but in the context of their distribution across lessons within the topic and the set of mathematical word problems for each lesson.

\subsection{The Process of Solving Mathematical Word Problems}

The basis for constructing an effective method for teaching students to solve mathematical word problems should be the students' understanding of the process of solving. The study of this issue takes place in several directions - in the direction of the stages of processing the mathematical word problem, actions and mental operations carried out by the student during the mathematical word problem solving; in the direction of studying the differences in solving the mathematical word problems by students with different abilities; in the direction of using certain means in the process of solving mathematical word problems by students; in the direction of studying strategies for solving mathematical word problems.

The process of solving mathematical word problems is disclosed in the works of the Ukrainian psychologist G. Ball [7] and of the Russian psychologist and methodologist L. Friedman [8]. The scientists consider the external and internal structures of the process of solving mathematical word problems. The external structure describes the solution of the math problem according to logic schemes, algorithmic and heuristic precepts. This is determined by the sequence of transformation of the math problem system. The use of mental operations involves the construction of an internal structure. It should be noted that in the real process of solving a math problem, the internal and external aspects interact closely with each other forming a single unit.

The analysis of the external structure of the process of solving mathematical word problems was carried out in the works of such methodologists as A. Artyomova (1998), M. Bantova (1977), M. Bogdanovich (1990), M. Burda (1986), N. Istomina (2002), Y. Koliagina (1977), S. Skvortsova (2006, 2011), L. Friedman (2002), S. Tsarova (1998), A. Tsukare (1998) and others. The process of solving a compound mathematical word problem based on its decomposition into several simple math problems and their sequential solution is considered by M. Bantova (1977), M. Burda (1986), G. Martynova (1982), N. Menchinska (1940), C. Tsarova $(1998,2005)$ and others. The process of solving typical math problems as students' recognition of their mathematical structures and the actualization of the generalized method of solving were studied by such methodologists as M. Bantova $(1989,1984)$, M. Bogdanovich (1990, 2006), A. Bogolyubov (1955), N. Istomina (1986, 2002), M. Moro (1978), N. Nikitin (1952), 
G. Polyak (1950), O. Pchilko (1963), L. Skatkin (1963, 1979), S. Skvortsova (2014, 2016, 2017), V. Stakevich (1970) and others.

This problem is also addressed in a range of studies of European, Asian and American scientists. While Ukrainian scientists developed theoretical aspects of teaching primary school students to solve mathematical word problems, other researchers demonstrated experimental observations of the process of solving math problems by students. So, Mushlihah Rohmah, Sugeng Sutiarso, Lampung University [9] focused their attention on studying the types of mistakes that students make while solving math problems. Slovenian scholars Kavkler, M., Magajna, L. and Kosak Babuder, M. [10] investigated the differences in the solving of mathematical word problems by students with MLD (mathematical learning difficulties) and successful solvers of MWP (mathematical word problem). Mary Hegarty, Richard E. Mayer, and Christopher A. Monk, University of California [11] studied the problem of understanding the text of mathematical problems. They compared the processes of solving undertaken by successful and unsuccessful math problem solvers. The authors found that students who fail in solving math problems more often use the strategy of direct translation of the text of the mathematical problem, highlighting keywords and word-signs of certain types of relationships, while successful math problem solvers build a model of the problem. Thus, simulation is one of the auxiliary means in the process of solving mathematical problems. The work of Werner Blum, University of Kassel [12] is devoted to the study of simulation processes. The author defines the difficulties of students with modeling, examines the modeling process in accordance with the style of their mathematical thinking, making a conclusion about the need and the possibility of special training of learners in modeling. It should be noted that modeling of the text of mathematical problem - coding of the verbal formulation of the mathematical problem text in the form of a diagram or drawing is one of the heuristics in solving math problems. Czech researchers Jarmila Novotná, Petr Eisenmann, Jiří Přibyl, Jiřina Ondrušová and Jiří Břehovský of Charles University in Prague studied the problem of solving math problems using heuristic strategies: analogies, reformulation of the problem, drawing a solution, etc. [13]. Ukrainian methodologists-mathematicians also show interest in this direction. The system of mathematical problems as a means of forming the heuristic activity of middle school students was studied by I. Gorchakova (2002), and the formation of research skills of school children in the process of solving mathematical problems with parameters, by A. Karlaschuk (2001).

The study of the process of solving math problems by primary school students, in particular contextual problems with covariate values, was carried out in the $\mathrm{PhD}$ research of $\mathrm{A}$. Kolovou [14]. Contextual mathematical problems require thinking and modeling of higher order and cannot be solved using a simple routine way. That is why the author considers the possibility of informal contextual strategies to address these issues. Problem solving as a means of developing students' thinking was researched in Russian dissertations by V. Radchenko (1987), I. Semenova (1990), S. Valitova (1998) and K. Zagorodnih (2004).

Consequently, solving a math problem is a complicated process of human mental activity, which is aimed at transforming an object described in the content of the problem into a solution to the contradiction between the condition and the requirement of the mathematical problem. The external structure describes the solution of the problem through logic circuits, algorithmic and heuristic prescriptions, thus defining the sequence of transformation of the problem system. The activity on the solution of mathematical word problems involves the following steps that make up the macrostructure of this activity: 1. Introduction to the math problem. Analysis of the text of the math problem. 2. Search for solving the math problem. 3. Implementation of the plan for solving the math problem. Recording of the solving pattern and the answer. 4 . Work on the math problem after it is solved (check of the solution, substantiation of methods of solving, consideration of other methods of solving, the study of the math problem and its solution, etc.).

The central issue of the microstructure analysis of math problems is to determine the actions that make up this activity. One can identify actions that implement individual stages of work on the math problem, and actions that relate to the group of special heuristic rules and schemes. Taking into account the age-old characteristics of the younger learner thinking, it was found that the dominant heuristics in 
solving math problems in primary school are simulation of the math problem situation (schematic drawing) and the process of solving search (the scheme of analysis or synthesis and the tree of reasoning).

In addition, the basis of the process of solving mathematical word problems are general mental actions (in particular, analysis, synthesis, comparison, abstraction, generalization, establishment and use of analogies), which constitute the

internal (psychological) structure of the process of solving mathematical word problems. Proceeding from the fact that the process of solving a math problem is the process of transforming the math problem system, the psychological structure includes specific actions of coding (decoding), anticipation and transfer along with general mental actions.

In the real process of solving a math problem, the internal and external aspects interact closely with each other, forming a single unit. In our study, we focused on forming the external structure of the math problem-solving activity.

\subsection{The Ability to Solve Mathematical Word Problems}

Ukrainian and Russian scientists who studied the problem of teaching younger students to solve mathematical word problems (O. Astriab (1939), M. Bantova (1977, 1984, 1989), M. Bogdanovich (2001), M. Burda (1986), N. Istomina (1998, 2002), Y. Kolyagin (1989, 1995), V. Krupich (1991, 1995), G. Martynova (1982, 1989), V. Osinskaya (1989), G. Sarantsev (1992, 1995), S. Skvortsova (2006, 2011), Z. Slepkan (2000, 2003), L. Friedman (2001), T. Khmara (2003), S. Tsareva (2004), P. Yerdinev (1995, 1996) and others) mutually agree that the ultimate goal of such learning should be the ability to solve mathematical problems.

By the ability to solve mathematical word problems we understand the complex skill that contains a set of skills of the lower order relating to consistently performed actions, namely: 1) the ability to analyze the text of the math problem; 2) the ability to present the results of the analysis as an auxiliary model - a short record, or a schematic drawing; 3 ) the ability to correlate the math problem with those studied earlier and to reproduce the method of solving math problems of this type (if the student is offered a problem of familiar type); 4) the ability to search for methods of solving the math problem if the latter is of an unknown type or the learner does not "recognize" the math problem: in the arithmetic method of solving - to perform analytical considerations (from the query to numerical data) or synthetic ones (from numerical data to the query of the math problem); in the algebraic method of solving - to formulate equations; in the geometric method of solving - to perform drawings, build diagrams or graphs; 5) the ability to perform operations that provide a solution to the math problem; 6 ) the ability to check the correctness of the solution.

Scientists distinguish between two main types of abilities to solve math problems: the general ability to solve any math problem, and the ability to solve math problems of certain types. In forming the general ability to solve math problems, the subject of learning and the main content should be not only solving math problems, but also the process of solving math problems, methods, and ways that help to complete each stage, as well as the whole process of solving in general (N. Istomina, L. Friedman, and S. Tsareva); the process of solving should be deployed as a process of modeling math problems (E. Alexandrova, O. Barinova, and L. Friedman). The same is the teaching of mathematical problem solving as stated in the Core Curriculum, where our scientifically grounded approaches are implemented.

L. Friedman [15] and S. Tsarova [16] defined some general directions of work on the formation of math problem-solving skills (the general ability to solve any math problem, and the ability to solve math problems of certain types).

In the research of S. Skvortsova [4], the problem of solving mathematical word problems is solved with the help of a holistic methodical system that covers all the varieties of mathematical word problems offered in primary school.

The main idea of the proposed methodical system is the special formation of general skills and abilities to solve math problems of certain types. In this regard, the operational composition of the 
general ability to solve math problems and the operational composition of the skills to solve math problems of certain types are determined. The basis of compiling a system of problems for the formation of general skills and abilities of younger students to solve math problems of certain types is the drilling of learners in performing individual actions that make up these skills [20; 21].

The theoretical basis for the method of forming general skills to solve math problems is the phased formation of mental actions, by the theory of P. Halperin [17], and the methods of forming the ability to solve certain types of math problems, by the theory of phased formation of mental actions and concepts of P. Halperin [17] and by the theory of content generalizations of V. Davydov [18]. The developed methodical system of teaching primary school students solving mathematical word problems is implemented in the line of Student Books and Activity Books for Grades 1-4, recommended by the Ministry of Education and Science of Ukraine (the authors are S. Skvortsova and O. Onoprienko).

\section{Teaching Grades 3-4 Students to Solve Mathematical Word Problems That CONTAIN A CONSTANT}

\subsection{TheORetical And Methodical Foundations for Forming the Ability to SOlve MATHEMATICAl Word Problems that CONTAIN A CONSTANT}

The aim of our study is to substantiate the method of generalizing the mathematical structure and methods of solving mathematical word problems that contain a constant: the math problems on finding the fourth proportional, on proportional division and on finding the unknown numbers by two differences.

The ability to solve math problems of certain types consists of the knowledge of various mathematical structures of typical math problems and the knowledge of generalized plans for their solution. To facilitate assimilation by students of different mathematical structures of typical math problems and corresponding plans for solving them, we propose to summarize these structures and methods of solving mathematical problems.

The mathematical structure of a typical mathematical word problem contains some common essential features: the situation of the math problem is described by three values that are in proportional dependence; it contains two cases; one of the values is a constant for both cases, and for another value two numerical values are given for both cases.

Distinctive features of mathematical structures are as follows: in math problems on finding the fourth proportional one numerical value is given for the third value, and the second value is an unknown number; in math problems on proportional division and in problems on finding the unknown numbers by two differences the two numerical values of the third value are unknown numbers; moreover, in the math problems on proportional division their sum is given, and in the math problems on finding the unknown numbers by two differences - their difference is given (Figure 1.).

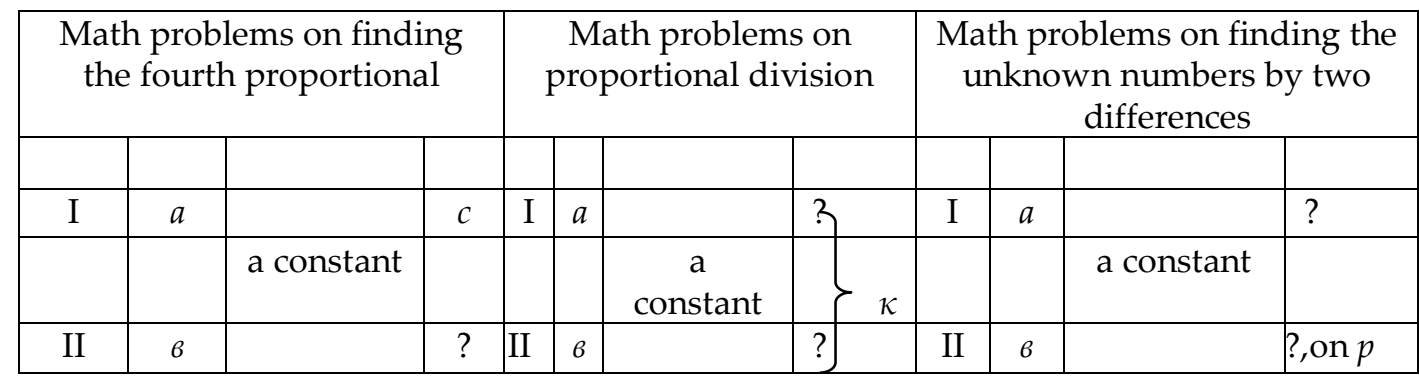

Fig. 1. Mathematical structures of typical math problems.

Having common features provides an opportunity to generalize the method of solving math problems of these types. Since all of these math problems have a constant for the two cases, the key to their solution may be finding its value. But the difference in the solution of these types of math problems lies in the method of finding the value of a constant: in the math problems on finding the fourth proportional, a constant is found by the other two values of one of the cases; in the math 
problems on proportional division, a constant is found by two summed numerical values of the other two values; in the math problems on finding the unknown numbers, a constant is found by two differences - by the numerical values of the difference ratio of the other two values.

The methodical basis for the experimental method of the formation of primary school students' ability to solve typical mathematical word problems that contain a constant value provide the following theses: both the subject and the main content of learning are types of math problems and methods of their solving (S. Tsareva); the structure of math problems should become the subject of deep study by students (L. Friedman); the assimilation of the method of solving must be the goal of action, and the actual solving of a particular math problem, only a by-product (Y. Mashbits). The process of teaching to solve certain types of math problems in the first stages should be deployed in the modeling plan (L. Friedman); the main method of teaching should be the method of solving a special system of preparatory drilling problems (L. Friedman).

Possessing knowledge about the mathematical structures of typical mathematical word problems and methods of solving them contributes to the successful solving of typical math problems that primarily depends on the quality of student's orientation activity. This activity is determined by the quality of presenting the scheme of action, which is performed afterwards. As proved by P. Galperin's studies, the most productive actions are formed by the III type of orientation.

This approach is fully consistent with the theory of meaningful generalizations of V. Davydov, who considers the theoretical path of generalization in solving problems as a generalization through the analysis of conditions and requirements, which allows abstracting the significant dependences represented in the problems. Due to this, the skill of solving such problems immediately acquires a generalized value and is transferred to the whole class of problems.

\subsection{Experimental Study of the Process of Generalization of the Method of SOlVing Mathematical Word Problems that CONTAin a CONSTANT}

62 fourth grade elementary students of the Specialized School №70 of the City of Kryvyi Rih, Ukraine took part in the experimental study in the academic year of 2019-2020.

Before carrying out experimental work, the students learned to solve mathematical word problems on finding the fourth proportional, on proportional division and on finding the unknown numbers by two differences. Before the start of the experiment, during the incoming section, the learners were asked to solve some specified typical math problems. The incoming section took place in the form of testing and interviewing students.

As a result of the analysis of the testing, we made the following conclusions: 1) the majority of Grade 4 students have a low and average level of mastery of the ability to solve math problems, and only about $25 \%$ of the students have reached a sufficient and high level; 2 ) the ability to analyze the content of a mathematical word problem is not sufficiently formed in most students. A significant proportion of students in the fourth grade is able to identify only the condition and the question. The skill being not formed yet makes it difficult to do a short recording of a math problem, a schematic drawing, and to determine the relationship between numerical values; 3) many students have difficulty in choosing the necessary arithmetic operations and establishing procedures for their implementation; 4) almost half of the students find it difficult to design and solve inverted math problems; and solving problems by other methods causes even more difficulty.

As a result of the incoming section, we selected two classes of students with approximately same results gained: 32 students studying in the experimental class (EC) and 30 students, in the control class (CC). In the EC, we have implemented the methodology of generalizing mathematical structures and methods of solving math problems that contain a constant, and in the CC such work was not carried out.

The students of the EC were asked to solve the math problem on finding the fourth proportional to determine the total value. In it, the constant is the value of one unit, which is found by the method of finding the same (constant) value. 
Mathematical problem № 1. A bus driver carried 88 people for 8 trips. How many people will it carry for 10 trips, if it carries the same number of people per trip?

It should be noted that about $15 \%$ of the students, immediately after reading the condition of the math problem, identified its type and recalled the plan for solving math problems on finding the fourth proportional. These students continued to work independently. While working on this math problem, the rest of the students, with the help of the teacher's questions, adjusted themselves to a detailed analysis of the formulation of the math problem, the allocation of quantities describing the situation of the problem and its numerical values (Figure 2).

\begin{tabular}{|l|c|c|c|}
\hline & The overall number of people & $\begin{array}{c}\text { Number of people per } \\
\text { one bus trip }\end{array}$ & Number of bus trips \\
\hline I & 88 & & 8 \\
\hline & & a constant & \\
\hline II & ? people & & 10 \\
\hline
\end{tabular}

Fig. 2. The short record of the math problem on finding the fourth proportional.

After writing a short record, $50 \%$ of the students found that it was a math problem on finding the fourth proportional. They recalled a plan for solving problems of that type and began to work independently.

In order to become aware of the relationship between numerical data, the students were asked to explain the numerical data and the unknown number by way of writing a short record of the math problem, and then to present the links between them in the form of a schematic drawing - an auxiliary model of the math problem. (Figure 3).

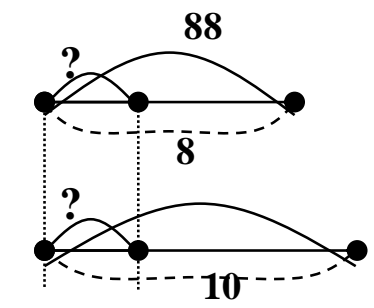

Fig. 3. The schematic drawing.

While the students were making a schematic drawing, the teacher's eliciting directed them towards estimating the value of the unknown number as compared with the total number of people in the first case. $5 \%$ of those students immediately assumed that the unknown number would be over 88 , as the driver made more bus trips with the same number of people that he carried for one trip.

After working on the analysis of the math problem formulation and the presentation of its results in the form of auxiliary models, $30 \%$ of the students recognized the math problem on finding the fourth proportional, actualized the method of its solving and started to solve it independently. $5 \%$ of the learners continued to work under the guidance of the teacher, doing the reasoning from the query of the math problem to numerical data, and after the drawing up of the plan of solving, they wrote the solution.

So, solving the math problem, by doing the first action we find out the number of people the driver carried for one trip - the constant value $(88: 8=11$ (people)); the second action is to find out the total number of people carried by the driver for 10 trips $(11 * 10=110$ (people)).

After solving this math problem, the teacher suggests to find the sum of values of the total value (the total number of people: $88+110=198$ (people)) and to include it in the problem, while changing the requirement - to find the value of the total value for each of the two cases. A short record of the math problem on finding the fourth proportional transforms into a short record of another math problem. By short record, math problem № 2 on proportional division is drawn up. The constant is the value of one unit. 
Mathematical problem № 2. For two shifts, the driver of the bus carried 198 people. For the first shift he made 8 trips, and for the second shift -10 trips. How many people did the bus carry during each shift, if it carried the same number of people for one trip? (Figure 4).

\begin{tabular}{|c|c|c|c|c|}
\hline & $\begin{array}{r}\text { The over } \\
\mathrm{p}\end{array}$ & $\begin{array}{l}1 \text { number of } \\
\text { ople }\end{array}$ & $\begin{array}{l}\text { Number of } \\
\text { people per } \\
\text { one bus trip }\end{array}$ & $\begin{array}{c}\text { Number of bus } \\
\text { trips }\end{array}$ \\
\hline \multirow[t]{2}{*}{ I } & ? people & & & 8 \\
\hline & & 198 people & a constant & \\
\hline II & ? people & & & 10 \\
\hline
\end{tabular}

Fig. 4. The short record of the math problem on proportional division.

You can draw a schematic image (Figure 5):

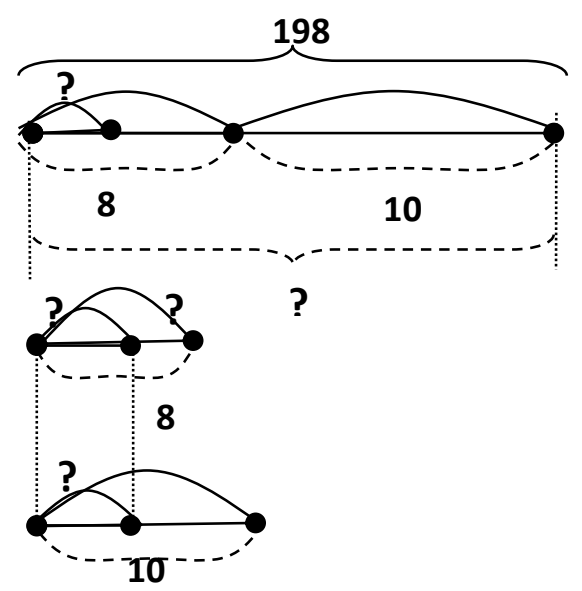

Fig. 5. The schematic drawing.

The students estimate the expected result: for the first shift, the bus driver will carry fewer people than the other because it made fewer trips with the same number of people per trip.

The learners determine the changes that have taken place in the previous math problem and its influence on solving this math problem. In the math problem on finding the fourth proportional, we have made the following changes: two unknown numerical values of one value (the total value) should be found, but providing their sum, we get a math problem on proportional division. Solving math problems on proportional division, we cannot find the constant value by the two known values of one of the cases; we can find the constant value by the two summed values of the two quantities.

Let us summarize the mathematical structures and plans for solving math problems on finding the fourth proportional and proportional division (Figure 6).

\begin{tabular}{|c|c|c|c|c|c|c|c|}
\hline \multicolumn{4}{|c|}{$\begin{array}{l}\text { Math problems on finding the fourth } \\
\text { proportional }\end{array}$} & \multicolumn{4}{|c|}{ Math problems on proportional division } \\
\hline & $\begin{array}{l}\text { Total } \\
\ldots .\end{array}$ & $\ldots . .1$ & $\begin{array}{l}\text { Number/ } \\
\text { time }\end{array}$ & & $\begin{array}{l}\text { Total } \\
\ldots .\end{array}$ & $\ldots .1$ & $\begin{array}{l}\text { Number/ } \\
\text { time }\end{array}$ \\
\hline \multirow[t]{2}{*}{ I } & $\square$ & & $\square$ & $\mathrm{I}$ & $?$ & & $\square$ \\
\hline & & a constant & & & $\zeta \square$ & a constant & \\
\hline II & $?$ & & $\square$ & II & $?$ 丁 & & $\square$ \\
\hline \multicolumn{4}{|c|}{$\begin{array}{l}\text { Solution plan } \\
\text { The method of finding the constant value } \\
\text { 1) the value of the constant - the value of } \\
\text { one unit for two numerical values of one }\end{array}$} & \multicolumn{4}{|c|}{$\begin{array}{l}\text { Solution plan } \\
\text { The method of finding the constant value } \\
\text { 1) the sum of the numerical values of one } \\
\text { of the quantities - quantity or time. }\end{array}$} \\
\hline
\end{tabular}


of the cases.

2) the unknown value of the total value, we answer the second question of the math problem.
2) the value of the constant - the value of one unit by the total values of the two quantities.

3) the unknown value of the total value, we answer the first question of the math problem.

4) the unknown value of the total value, we answer the second question of the math problem.

Fig. 6. Structures and solution plans for math problems on finding the fourth proportional and on proportional division.

The math problem on proportional division is solved according to the following plan: by the first action, we find out the sum of the numerical values of another value - the number of trips $(8+10=18$ (t.)). By the second action, we find out the constant value (the number of people per trip) for two sums (198: $18=11$ (people)). By the third action, we find out the number of people the driver carried for the first shift; thus, we will answer the first question of the math problem $\left(11^{*} 8=88\right.$ (people)). By the fourth action, we find out the number of people the driver carried for the second shift; thus, we will answer the second question of the math problem $(11 * 10=110$ (people)).

The verification of the solution is carried out by means of adding the numerical values found and comparing the resulting number with the given numerical value of the sum $(88+110=198$ (people), which is given in the condition of the math problem).

The next study of the math problem occurs through the introduction in the condition of the math problem the difference of values of the total value, but not their sum.

Mathematical problem № 3. During the second shift, the bus driver carried 22 people more than during the first one. During the first shift, he made 8 trips; and during the second shift, 9 trips. How many people did the bus driver carry each shift, if it carried the same number of people per trip? (Figure 7)

\begin{tabular}{|l|l|l|l|}
\hline & Total number of people & $\begin{array}{l}\text { Number of people per } \\
\text { one bus trip }\end{array}$ & Number of trips \\
\hline I & ? people & & 8 \\
\hline & & a constant & \\
\hline II & ? people, 22 people more & & 10 \\
\hline
\end{tabular}

Fig. 7. The short record of the math problem on proportional division.

You can draw a schematic image (Figure 8):
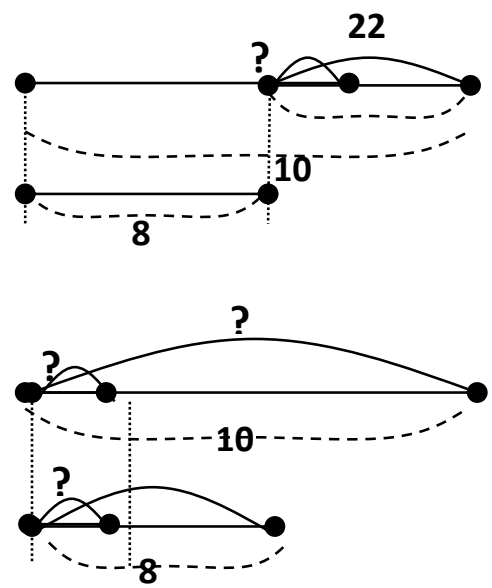

Fig. 8. The schematic drawing. 
Before solving this math problem, the students compare the new math problem with the math problem on proportional division. These math problems are similar to the fact that both contain three proportional values. One of them has two numerical values, and both values of the other value are unknown. The value of one unit is a constant value for both cases. These math problems differ by the fact that in the math problem on proportional division the value of the sum of total values is given, and in this one - the value of the difference of total values is given.

Consequently, in both cases there is a constant value for two cases. To solve math problems that contain a constant value, the key is to find its value. The students recall the known methods of finding the constant value:

1) by the numerical values of the two quantities in relation to one of the cases;

2) by the two summed values of two quantities;

3) by two differences.

We apply the third method of finding the constant value, because we have not given either the value of two quantities in relation to one of the cases or the total value of one of the variables, but we have given the difference between the numerical values of one value in two cases. So, we find out the constant value by two different methods. Thus, the changed condition of the math problem caused the use of another method of finding the constant value - by two differences.

Let us summarize the mathematical structures of math problems on finding the unknown numbers by two differences and on proportional division (Figure 9).

\begin{tabular}{|c|c|c|c|c|c|c|c|}
\hline \multicolumn{4}{|c|}{$\begin{array}{l}\text { Math problems on finding proportional } \\
\text { division }\end{array}$} & \multicolumn{4}{|c|}{$\begin{array}{l}\text { Math problems on finding the unknown } \\
\text { numbers by two differences }\end{array}$} \\
\hline & Total.... & $\ldots .1$ & $\begin{array}{l}\text { umber/ } \\
\text { ne }\end{array}$ & & tal... & $\ldots .1$ & $\begin{array}{l}\text { Number/ } \\
\text { time }\end{array}$ \\
\hline \multirow[t]{2}{*}{1} & ? & & & I & $?$ & & $\square$ \\
\hline & $\square$ & a cons & & & & a co & \\
\hline II & $?$ & & & II & ?, or $\square$ & & $\square$ \\
\hline \multicolumn{4}{|c|}{$\begin{array}{l}\text { The method of finding the constant value } \\
\text { 1) the sum of the numerical values of one of the } \\
\text { quantities - quantity or time. } \\
\text { 2) the value of the constant value - the value of } \\
\text { one unit by the total values of the two } \\
\text { quantities. } \\
\text { 3) the unknown value of the total value, we } \\
\text { answer the first question of the math problem. } \\
\text { 4) the unknown value of the total value, we } \\
\text { answer the second question of the math } \\
\text { problem. }\end{array}$} & \multicolumn{4}{|c|}{$\begin{array}{l}\text { The method of finding the constant value } \\
\text { 1) the difference of the numerical values } \\
\text { of one of the quantities - quantity or time. } \\
\text { 2) the value of the constant value - the } \\
\text { value of one unit by two differences. } \\
\text { 3) the unknown value of the total value, } \\
\text { we answer the first question of the math } \\
\text { problem. } \\
\text { 4) the unknown value of the total value, } \\
\text { we answer the second question of the } \\
\text { math problem. }\end{array}$} \\
\hline
\end{tabular}

Fig. 9. The structures of math problems on finding the unknown numbers by two differences and on proportional division.

We solve the math problem on finding the unknown numbers by two differences according to the following plan: by the first action, we find out the difference between the numerical values of another value - the number of trips $(10-8=2(\mathrm{t}))$. By the second action, we find out the constant value (the number of people per trip) by two differences (22: $2=11$ (people)). By the third action, we find out the total number of people the driver carried for the first shift, thus we will answer the first question of the math problem $(11 * 8=88$ (people)). By the fourth action we find out the total number of people the driver carried for the second shift, thus we will answer the second question of the math problem (11 * $10=110$ (people)). The verification of the solution is carried out by means of finding the difference 
between the numerical values found and comparing the resulting number with the difference ratio given in the condition of the math problem.

Comparing the methods of solving math problems on proportional division and on finding the unknown numbers by two differences, the students determine that the two last actions are the same in both math problems, because they have the same questions and the same constant value needed to answer the questions in both problems. The solutions differ in the first two actions, because the constant value was found out differently: in the first math problem - by two sums, and in the second math problem - by two differences.

We have reviewed the work on the math problems on finding the fourth proportional, on proportional division, on finding the unknown numbers by two differences, in which the value of one unit of measurement or number is a constant, and the unknown numbers are the value of the total value. Similarly, it is possible to construct a method for generalizing mathematical structures and solving these types of math problems where the unknown number(s) is(are) the value of the quantity or time (the constant is the value of one unit of measurement or number).

Finally, we can compare all the three types of math problems - the math problem on finding the fourth proportional, the math problem on finding the unknown numbers by two differences, the math problem on proportional division and generalize their mathematical structures and methods of solving (Figure 10).

\begin{tabular}{|c|c|c|c|c|c|c|c|c|c|c|c|}
\hline \multicolumn{4}{|c|}{$\begin{array}{l}\text { Math problems on finding the } \\
\text { fourth proportional }\end{array}$} & \multicolumn{4}{|c|}{$\begin{array}{l}\text { Math problems on } \\
\text { proportional division }\end{array}$} & \multicolumn{4}{|c|}{$\begin{array}{l}\text { Math problems on finding } \\
\text { the unknown numbers by } \\
\text { two differences }\end{array}$} \\
\hline & & $\ldots .1 \ldots$ & & & & $\ldots .1 \ldots$ & & & & $\ldots .1 \ldots$ & \\
\hline \multirow[t]{2}{*}{ I } & $a$ & & $B$ & I & $a$ & & ? & I & $a$ & & $?$ \\
\hline & & a constant & & & & $\begin{array}{l}\text { a } \\
\text { constant }\end{array}$ & & & & a constant & \\
\hline II & $c$ & & $?$ & II & $c$ & & ? & II & $c$ & & 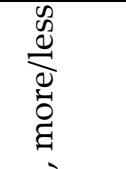 \\
\hline \multicolumn{4}{|c|}{$\begin{array}{l}\text { Solution plan } \\
\text { the method of finding } \\
\text { the constant value } \\
\text { 1) the value of the constant - } \\
\text { the value of one unit - by the } \\
\text { two numerical values of one } \\
\text { of the cases. } \\
\text { 2) the unknown value, we } \\
\text { answer the questions of the } \\
\text { math problem. }\end{array}$} & \multicolumn{4}{|c|}{$\begin{array}{l}\text { Solution plan } \\
\text { the method of finding } \\
\text { the constant value } \\
\text { 1) the sum of the } \\
\text { numerical values of } \\
\text { one of the values. } \\
\text { 2) the value of the } \\
\text { constant - the values } \\
\text { of one unit - by the } \\
\text { total values of the two } \\
\text { quantities. } \\
\text { 3) the unknown } \\
\text { value, we answer the } \\
\text { first question of the } \\
\text { math problem. } \\
\text { 4) the unknown value, } \\
\text { we answer the second } \\
\text { question of the math } \\
\text { problem. }\end{array}$} & \multicolumn{4}{|c|}{$\begin{array}{l}\text { Solution plan } \\
\text { the method of finding } \\
\text { the constant value } \\
\text { 1) the difference of the } \\
\text { numerical values of one of } \\
\text { the values. } \\
\text { 2) the value of the constant } \\
\text { - the value of one unit - by } \\
\text { two differences. } \\
\text { 3) the unknown value, we } \\
\text { answer the first question of } \\
\text { the math problem. } \\
\text { 4) the unknown value, we } \\
\text { answer the second question } \\
\text { of the math problem. }\end{array}$} \\
\hline
\end{tabular}

Fig. 10. The structures of math problems on finding the fourth proportional, on proportional division, and on finding the unknown numbers by two differences. 
To determine the effectiveness of the developed methodical system, we conducted a final section in the form of testing. The students of the EC and the CC were asked to solve math problems on finding the fourth proportional, on proportional division and on finding the unknown numbers by two differences.

The content of tasks for the control section:

The math problem on finding the fourth proportional:

№171 Can you solve the problem in a different way?

It took the teacher two hours to mark and grade 64 notebooks. How many notebooks will the teacher mark and grade in three hours if they work with the same productivity?

The math problem on proportional division:

№162

Two gardeners ordered 28 similar seedlings from the nursery. How should they split the seedlings if one of them paid $360 \mathrm{UAH}$ and the other - $480 \mathrm{UAH}$ ? Change the problem so that you get the problem on finding the unknown numbers by two differences.

The math problem on finding the unknown numbers by two differences:

№160

One cyclist was on the road 5 hours and another cyclist -3 hours. The other cyclist covered $18 \mathrm{~km}$ less than the first one. How many kilometers covered each cyclist if they were riding at the same speed? Change the problem so that you get the problem on proportional division

During the control section, we observed the students solving the abovementioned math problems as well as interviewed them. Each student was interviewed by a teacher who was also conducting a survey report. Before solving the problems independently, the learners were instructed on how to work on a math problem and how to record the results (Figure 11).

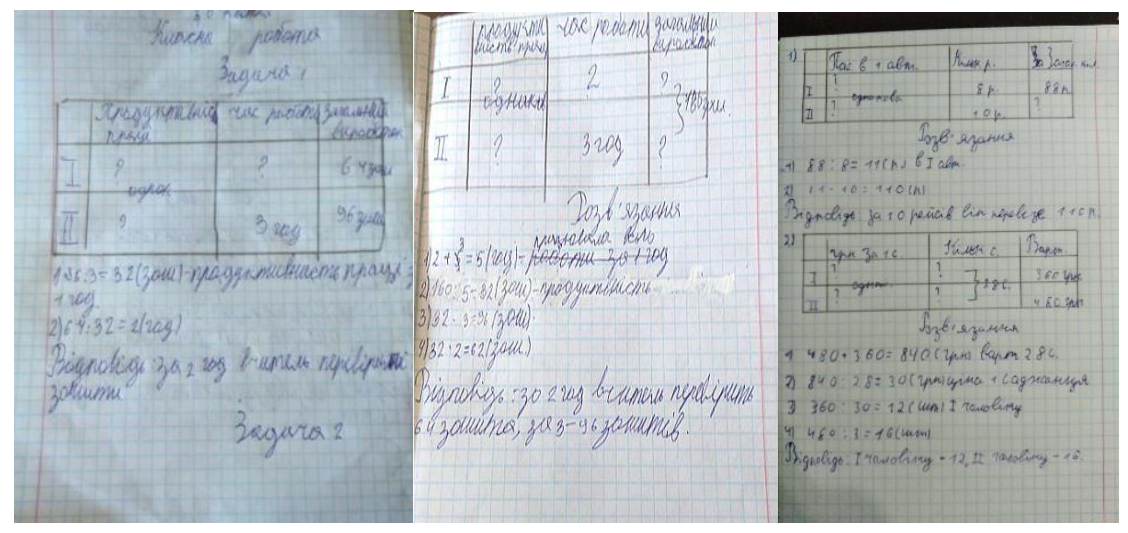

Fig. 11. Samples of students' works.

Instruction: "When solving a math problem, say out loud all the steps you need to solve it. Record the solution of the problem in the following way: 1) a short record of the problem in the form of a chart; 2) if possible, complete a schematic drawing for the problem; 3) record each action of solving the problem with an explanation; 4) write down the problem-solving expression; 5) if possible, check the correctness of the solution of the problem; 6) write down the answer".

During the interview, the researcher could ask the student additional questions or offer some tasks designed to determine the completion of a particular operation that the student had to perform. In doing so, we proceeded from the author's understanding of the ability to solve mathematical problems as a set of lower-order skill relating to consistently performed actions, namely: 1) the ability to analyze the text of the math problem; 2) the ability to present the results of the analysis as an auxiliary model a short record, or a schematic drawing; 3) the ability to correlate the math problem with those studied earlier and to reproduce the method of solving math problems of this type (if the student is offered a problem of familiar type) or to search for methods of solving the math problem if the latter is of an 
unknown type, or the learner does not "recognize" the math problem; 4) the ability to perform operations that provide a solution to the math problem; 5) the ability to check the correctness of the solution.

At the same time, the main actions that determine the strategy for solving the mathematical problem are the following:

1) analysis of the text of the problem

2) presentation of the result of the analysis in the form of an auxiliary model - a short record or a schematic drawing

3) correlating the problem with the previously learned one and reproducing the method of solving the problem of the given type (if the student is offered a problem of a familiar type) or performing a search for solving the problem if the math problem is of an unknown type or the student did not "recognize" the problem.

The following operations are: 4) performing actions that provide a solution to the math problem, and 5) verifying that the problem is solved correctly and has executive function only. Therefore, we choose criteria for the formation of the ability to solve problems on finding the fourth proportional, on proportional division and on finding the unknown numbers by two differences such as: 1) analysis of the text of the problem; 2) creation of an auxiliary model of the problem (a short record, a schematic drawing); 3) updating knowledge about familiar mathematical structures of the problem and generalized plans for solving them, or performing a search for solving the problem (from question to numerical data of the problem - analysis, or from numerical data to the problem - synthesis). For each of these criteria we define the following indicators:

1) analysis of the text of the problem:

Low level. The student perceives the math problem superficially, incompletely; the student cannot distinguish the condition and questions of the problem; it is difficult for them to identify the objects of the problem (doers of the actions and the situation of the problem), to separate the numerical data and the unknown number. In doing so, he/she identifies external, often irrelevant, elements of the problem.

Average level. The student seeks to understand the problem, separates the condition and the questions of the problem, has problems with identifying a group of interrelated quantities that describe the situation of the problem; the student distinguishes the numerical data and the unknown number, but is only able to make individual connections between them.

Sufficient level. The perception of the problem is accompanied by its analysis; the student identifies the condition, questions, and objects of the problem; he/she establishes a group of interrelated quantities that describe the situation of the problem; determines the numerical data and the unknown number, as well as connections between them.

High level. The student has a thorough content analysis of the problem, freely allocates the numerical data and the unknown number, determines the words-signs and types of relations given in the problem. When analyzing the situation of the problem, the student freely repels irrelevant and unnecessary elements in terms of its condition.

2) creation of an auxiliary model of the problem (a short record, a schematic drawing):

Low level. The student is not able to write a short record or a schematic drawing of the problem. Implementation of problem-solving operations at this stage is only possible with teacher step-by-step guidance and assistance. Before solving the problem, the student does not attempt to estimate the expected result.

Average level. When compiling a short record or a schematic drawing, the student does not rely on the word-signs in the text of the problem meant for orientation. The student can write a short record of the math problem by a sample, but drawing a schematic image, even by a sample, is difficult for them. In the absence of a unified system of connections between values, it is difficult to assume the expected result.

Sufficient level. The learner is able to identify keywords and a group of related variables that reveal the situation of the math problem; he/she is able to write a short record of the problem and / or perform a schematic drawing. 
High level. The student is able to draw different types of representative models of the mathematical problem - a short record and a schematic drawing. Based on a thorough analysis of the problem, the student identifies the relationship between the data and the unknown number and assumes the expected result. Flexibility of thinking reveals the correct establishment of both direct and inverse connections between values.

3) updating knowledge about familiar mathematical structures of the problem and generalized plans for solving them, or performing a search for solving the problem (from question to numerical data of the problem - analysis, or from numerical data to the problem - synthesis):

Low level. The student cannot and does not attempt to imagine the steps for solving the problem. More often than not, when the student does not understand the content of the problem, he/she immediately begins to solve it, which is more often a random manipulation of numerical data; he/she does not search for the ways of solving the problem, but immediately begins to record the solution of the problem, choosing a system of arithmetic actions randomly. Obviously, after solving the problem, the student has difficulty in formulating an answer. Solving the problem is possible only with the help of step-by-step help and supervision by the teacher.

Average level. The student does not correlate the problem with the previously solved ones, so he/she can determine the plan of solving the problem of a familiar mathematical structure with the teacher help, or relying on aids - a schematic drawing, or a scheme of analysis of the problem, or his own life experience. He/she lacks the flexibility of thinking, so there are difficulties in establishing inverse connections between values, and there is a tendency to familiar forms of presenting tasks, to the usual methods of solving.

Sufficient level. The student by essential features is able to identify the mathematical problem as that of a familiar type and update the generalized plan for solving the problem. The student is able to summarize the method of solving, but it requires more exercises to solve the same problems and the help of the teacher. It becomes available to the student to find different ways to solve the problem, if there is experience in solving similar problems.

High level. The student unmistakably develops a plan for solving the problem, justifies the arithmetic actions with the help of which they solve this problem. The learner creates and solves inverted problems; establishes a correspondence between the numbers that result from the solution of the problem and the given numbers, checks the correctness of the solution of the task. The student is able to determine different methods of solving on their own and to separate the most rational one. It is easy for them to summarize how to accomplish a specific problem. He/she reveals the flexibility of thinking by switching easily from one method to another.

In determining the level of completion of each problem-solving action, the researcher focused on the above criteria and the corresponding indicators for each criterion.

The results of the testing are given in Chart 1.

\begin{tabular}{|c|c|c|c|c|c|c|c|}
\hline \multirow{3}{*}{ 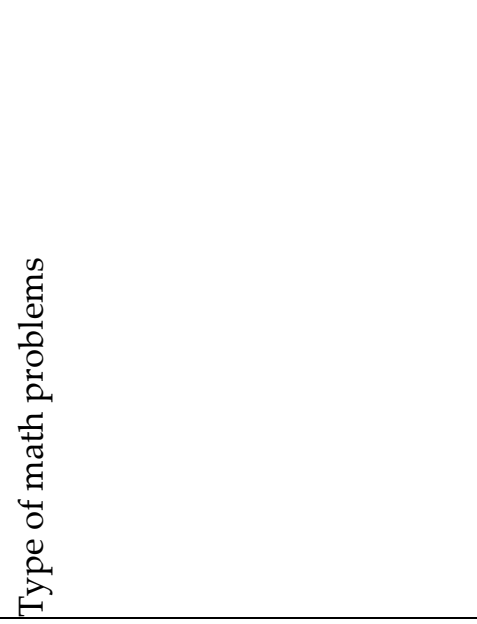 } & \multirow{3}{*}{ 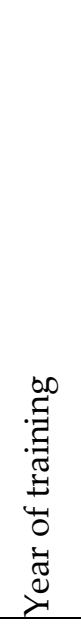 } & \multirow[b]{3}{*}{ 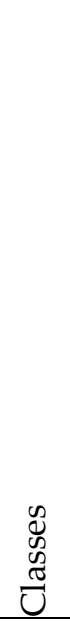 } & \multirow{3}{*}{ 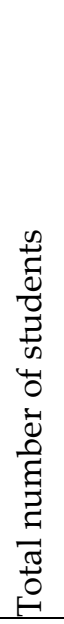 } & \multicolumn{4}{|c|}{$\begin{array}{l}\text { Number of students who have } \\
\text { gained knowledge and skills at the } \\
\text { level }\end{array}$} \\
\hline & & & & 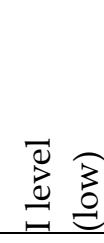 & 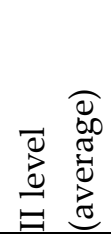 & 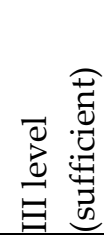 & 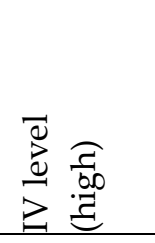 \\
\hline & & & & $\%$ & $\%$ & $\%$ & $\%$ \\
\hline Math problems on finding the & 4-th & E & 32 & 0 & 34,3 & 56,3 & 9,4 \\
\hline
\end{tabular}




\begin{tabular}{|l|l|l|l|l|l|l|l|}
\hline fourth proportional & & $\mathrm{C}$ & 30 & 13,3 & 53,4 & 30,0 & 3,3 \\
\hline $\begin{array}{l}\text { Math problems on } \\
\text { proportional division }\end{array}$ & 4 -th & $\mathrm{E}$ & 32 & 3,1 & 25,0 & 62,5 & 9,4 \\
\cline { 2 - 9 } & $\mathrm{C}$ & 30 & 13,4 & 56,7 & 26,7 & 3,3 \\
\hline $\begin{array}{l}\text { Math problems on finding the } \\
\text { unknown numbers by two } \\
\text { differences }\end{array}$ & $\mathrm{E}$ & 32 & 3,1 & 31,4 & 56,3 & 9,4 \\
\cline { 3 - 8 } & $\mathrm{C}$ & 30 & 16,6 & 53,4 & 26,7 & 3,3 \\
\hline
\end{tabular}

Tab. 1. Distribution of students of experimental and control classes by levels of formation of abilities to solve math problems containing a constant.

The students who have demonstrated the low level perceive the math problems superficially and incompletely. They can neither distinguish between the condition and the problem of the mathematical problem or identify the object of the math problem, or separate the numerical data and the unknown number of the math problem. They distinguish external, often non-essential elements of the math problems, cannot and do not try to imagine the course of solving the math problem. They cannot perform a short math problem record or schematic drawing. Immediately after reading the math problem, they begin to "solve"; they choose numerical data and arithmetic action at random. Before solving the math problem, they cannot make an estimation. Even if the math problem is solved, the students are having difficulty in formulating the answer. They "don't see" different methods of solving, even when the teacher points to them.

The students who have demonstrated the average level show the following: their perception of the math problem is accompanied by its analysis; they distinguish the condition and the question, the object of the math problem, numerical data and the unknown number. They seek to understand the math problem, to separate the data and the unknown number, but can only establish separate links between them. They are able to highlight keywords and write a short math problem record or perform a schematic drawing, but they are having difficulty estimating the expected result. The students don not relate the math problem with the previously studied ones, therefore do not recognize the typical math problem, and as a result do not update the way of its solution, resorting to considerations from the question of the math problem to the numerical data - analysis. They find different methods of solving the math problem that depends on their experience in solving similar math problems.

The students who have demonstrated the sufficient level can analyze the math problem. They are able to identify a group of proportional values that describe the situation of the math problem, and also form an auxiliary model of the math problem. Based on a complete comprehensive analysis of the math problem, the students determine the connections between the numerical data and the unknown number and estimate the expected result. After performing the auxiliary math problem model, they correlate the math problem with the previously studied ones and recognize the type of the math problem and update the plan for its solution. They formulate and solve the inverse math problems, as well as establish the correspondence between the numbers obtained because of solving the math problem and the given numbers.

High level. Immediately after reading the math problem, the students determine its type and actualize the generalized way of its solution. They are able to independently see different methods of solving and point out the most rational. When analyzing the situation, the pupils freely reject insignificant and unnecessary elements in terms of its requirement.

The developed and experimentally tested teaching methods of solving mathematic word problems that contain a constant value have been implemented in a series of mathematics textbooks and exercise books by S. Skvortsova and O. Onopriienko [19]. 


\section{CONCLUSIONS}

Solving mathematical word problems has a significant place in the structure of the content of elementary mathematics education. The result of teaching mathematics in the primary school in Ukraine is the general ability of students to solve mathematical word problems, as well as the ability to solve math problems of certain types (mathematical problems on finding the fourth proportional, on proportional division, on finding the unknown by two differences, on double reduction to one, on collaborative work and on motion). Achieving this result is possible provided that the theoretically grounded methodical system of teaching primary school students to solve the mathematical word problems is implemented.

In the experimental study we have tested the method of generalization of mathematical structures and methods of solving mathematical word problems that contain a constant value. We have implemented an approach that consists in solving a system of interrelated math problems, namely, the transformation of the math problem on finding the fourth proportional into the math problem on proportional division; the transformation of the math problem on proportional division into the math problem on finding the unknowns by two differences. Moreover, at each stage, we offer the comparing of the mathematical structures of the math problem of each pair, the defining of common and distinctive features in them, and investigate the influence of differences on the method of solving the math problem. Finally, after solving two pairs of math problems, students are asked to compare all the three math problems and to investigate the effect of differences on the way mathematical problems are solved. The considered method of generalization should be an integral part of the method of forming skills to solve the math problems of certain types. After its implementation in the experimental class, $56 \%$ of pupils demonstrated a sufficient level of abilities in solving math problems of these types.

The prospects to further research are seen in the development of drilling exercises for generalizing mathematical structures and methods for solving math problems on processes and checking their effectiveness experimentally.

\section{REFERENCES}

[1] Decree of the KMU "On Approval of the State Standard of Primary Education", 2018. Available at: https://www.kmu.gov.ua/ua/npas/pro-zatverdzhennya-derzhavnogo-standartu-pochatkovoyi-osviti.

[2] Programs of the New Ukrainian School. Available at: https://mon.gov.ua/ua/osvita/zagalna-serednyaosvita/navchalni-programi/navchalni-programi-dlya-pochatkovoyi-shkoli.

[3] The order "On Approval the Core Curricula for Grades 3-4 of General Secondary Education" from 27.12.2018, № 1461. Available from: https://mon.gov.ua/ua/npa/pro-zatverdzhennya-tipovih-osvitnih-programdlya-3-4-klasiv-zakladiv-zagalnoyi-serednoyi-osviti

[4] Skvortsova S. Methodology of Teaching Primary School Learners Solving Word Problems. Astroprint, Odesa, 2006.

[5] Kamuran T. Problem solving levels of elementary school students on mathematical word problems and the distribution of these problems in textbook. Çukurova Üniversitesi Eğitim Fakültesi Dergisi, 46 (2) (2017), 639-648. Available at: https://www.researchgate.net/publication/321215940_Problem_Solving _Levels_Of_Elementary_School_Students_On_Mathematical_Word_Problems_And_The_Distribution_ of_These_Problems_in_Textbooks.

[6] Rohrer D., Taylor K. The shuffling of mathematics problems improves learning. Instructional Science, 35 (6) (2007), 481-498. Available at: https://www.researchgate.net/publication/227181272 The_shuffling_of_mathematics_problems_improves_learning. doi: 10.1007/s11251-007-9015-8.

[7] Ball G.A. The Theory of Drilling Problems: Psychological and Pedagogical aspect. Pedagogy, Moscow, 1990. (in Russian)

[8] Fridman L.M. Basics of Problomology. Series "Problemology", Moscow, SINTEG, 2001. (in Russian.) 
[9] Rohmah M., Sutiarso S. Analysis Problem Solving in Mathematical Using Theory Newman. EURASIA Journal of Mathematics, Science and Technology Education, 14 (2) (2018), 671-681. Available at: http://repository.lppm.unila.ac.id/8167/1/Analysis\%20Problem\%20Solving.pdf.

[10] Kavkler M., Magajna L., Babuder M. Key Factors for Successful Solving of Mathematical Word Problems in Fifth-grade Learners. Health Psychology Report, 2 (1) (2014), 27-38. Available at: https://www.researchgate.net/publication/275254058_Original_article_Key_factors_for_successful_solvi ng_of_mathematical_word_problems_in_fifth-grade_learners.

[11] Hegarty M., Mayer R.E., Monk C.A. Comprehension of Arithmetic Word Problems: A Comparison of Successful and Unsuccessful Problem Solvers. Journal of Educational Psychology, 87 (1) (1995), 18-32, 1995. Available at: https://www.researchgate.net/publication/232493749_Comprehension_of_Arithmetic _Word_Problems_A_Comparison_of_Successful_and_Unsuccessful_Problem_Solvers

[12] Blum W. Mathematical Modelling: Can It Be Taught And Learnt? Journal of Mathematical Modelling and Application, 1 (1) (2009), 45-58. Available at: https://www.researchgate.net/publication /279478754_Mathematical_Modelling_Can_It_Be_Taught_And_Learnt.

[13] Novotna J., Eisenmann P., Priby J., Ondrusova J., Jiri J., Evangelista J.Jan. Problem solving in school mathematics based on heuristic strategies. ERIES Journal, 7 (1) (2014), 1-6. Available at:

https://www.eriesjournal.com/index.php/eries/article/ view/96.

[14] Kolovou A. Mathematical problem solving in primary school, Utrecht: Freudenthal Institute for Science and Mathematics Education, Faculty of Science, Utrecht University, FIsme Scientific Library, 66 (2011).

[15] Fridman L.M. Word Problems in Mathematics: history, theory, methodology. Moscow, School Press, 2002. (in Russian)

[16] Tsareva S.E. Teaching solving text problems oriented on forming academic activity in younger learners. Novosibirsk, 1998. (in Russian)

[17] Galperin P.Ya. General view on the so-called stage formation of mental actions, representations and concepts. Digest of Moscow University, Psychology, 14 (2) (1998), 3-8. (in Russian)

[18] Davydov V.V. Psychological Theory of Academic Activity and Methods of Elementary Teaching Based on Content Generalisation. Tomsk, 1992. (in Russian)

[19] Skvortsova S.O., Onoprienko O.V. Mathematics: textbook for Grade 4 of inst. of general second. educat. Publ. House "Ranok", 2015. Available at: https://www.ranok.com.ua/resources/files/pdf/Math_4-ch2_Uch.pdf.

[20] Skvortsova S.O. The general methodology for teaching younger students to solve problems, finding a sum or a difference or multiple comparison of the two particles and the inverse of them. SCIENCE AND EDUCATION, 3-4 (2005), 137-143. (in Ukrainian)

[21] Skvortsova S.O. The general methodology for teaching younger students to solve problems that involve finding a sum or a difference or multiple comparison of two products and their return to them. SCIENCE AND EDUCATION, 1-2 (2005), 141-148. (in Ukrainian)

Address: Svitlana Skvortsova, South Ukrainian Pedagogical University named after K. D. Ushynsky, 26 Staroportofrankivska St., Odessa 65000, Ukraine;

Oksana Onoprienko, Institute of Pedagogy of the National Academy of Pedagogical Sciences of Ukraine, 52-D Sichovykh Striltsiv St., Kyiv 04053, Ukraine;

Ruslana Romanyshyn, Vasyl Stefanyk Precarpathian National University, 57 Shevchenko St., Ivano-Frankivsk 76018, Ukraine.

E-mail: skvo08@i.ua; oks_on@ukr.net; ruslanaromanyshyn@ukr.net.

Received: 03.02.2021; revised: 21.03.2021. 
Скворцова Світлана, Онопрієнко Оксана, Романишин Руслана. Задачі, що містять сталу величину в курсі математики початкової школи України. Журнал Прикарпатського університету імені Василя Стефаника, 8 (1) (2021), 46-64.

Стаття присвячена дослідженню місця сюжетних математичних задач в курсі математики початкової школи України; визначенню результатів у навчанні розв'язування задач; з'ясування суті процесу розв'язування задач; проблеми формування в учнів початкової школи уміння розв'язувати задачі, що містять сталу величину - на знаходження четвертого пропорційного, на пропорційне ділення і на знаходження невідомих за двома різницями,; організації навчального дослідження учнів 3 метою визначення спільних і відмінних ознак математичних структур зазначених типів задачі та їх впливу на спосіб розв'язування. Базуючись на методичній системі навчання учнів початкової школи розв'язування задач С. Скворцової, спираючись на суть поняття «уміння розв'язувати задачі» та методичну систему формування умінь розв'язувати задачі певних типів, запропоновано систему навчальних завдань із узагальнення математичних структур та способів розв'язування задач, що містять сталу величину.

Кдючові слова: математика, початкова школа, сюжетні математичні задачі, задачі на знаходження четвертого пропорційного, задачі на пропорційне ділення, задачі на знаходження невідомих за двома різницями. 